ORIGINAL ARTICLE

\title{
A retrospective description of anesthetic medication dosing in overweight and obese children
}

\author{
Constance N. Burke ${ }^{1}$, Terri Voepel-Lewis ${ }^{1}$, Deborah Wagner ${ }^{1}$, Irwin Lau ${ }^{2}$, Andrew Baldock ${ }^{3}$, \\ Shobha Malviya ${ }^{1} \&$ Olubukola Nafiu ${ }^{1}$ \\ 1 Department of Pediatric Anesthesiology, Mott Children's Hospital, University of Michigan, Ann Arbor, MI, USA \\ 2 School of Pharmacy, University of Michigan, Ann Arbor, MI, USA \\ 3 Department of Anaesthesiology, Southampton Children's Hospital, University Hospital Southampton, Southampton, UK
}

\section{Keywords}

pediatric; anesthesiology; medication dosing; overweight; obese

\section{Correspondence \\ Constance N. Burke, C.S. Mott Children's Hospital, Room 4-911, SPC 4245, 1540 East Hospital Drive, Ann Arbor, Ml 48109-4245, USA \\ Email: cnburke@umich.edu}

Section Editor: Jerrold Lerman

Accepted 2 March 2014

doi:10.1111/pan.12396

\begin{abstract}
Summary
Introduction: Pediatric obesity is a major health concern in the United States and as many as $34 \%$ of those who require general anesthesia are overweight or obese $(\mathrm{OW})$. The lack of data and recommendations for dosing medications in obese children leaves significant gaps in the understanding of correct dosing in the clinical setting.

Objective: To determine whether OW children were more likely to receive doses of medications outside the recommended range.

Methods: Following IRB approval, patient medical records were queried to identify children 2 through 17 years who underwent noncardiac surgeries and received at least one medication of interest. Children with hepatic disease, renal disease, neurological impairment, sleep-disordered breathing, or missing height or weight measurements were excluded. Children were stratified into weight categories based on age and gender percentiles as per CDC guidelines. Those $\geq 85$ th percentile were classified as overweight/obese. Ideal and lean weight (for age, gender) were calculated. Drug doses were stratified as underdosed ( $>10 \%$ below minimum recommended dose), overdosed ( $>10 \%$ above maximum recommended dose), or within recommended dose (dose $\pm 10 \%$ ). Actual doses were compared to recommended doses as per actual, ideal, or lean weight (as recommended for specific drugs) in the overweight/obese groups vs the control weight $(\mathrm{CW})$ group.

Results: Ten thousand five hundred and nine doses were reviewed. Overweight/obese children were more likely to receive doses outside the recommended dose range than the $\mathrm{CW}$ group.

Conclusions: Overweight/obese children were more likely to receive doses of common anesthetic medications outside the recommended doses potentially adding risk of adverse outcomes in these children.
\end{abstract}

\section{Introduction}

Pediatric obesity is a major public health concern in the United States (1), with up to $34 \%$ of school-age children and adolescents being overweight [body mass index $(\mathrm{BMI}) \geq 85$ th percentile] or obese (BMI $\geq 95$ th percentile). Indeed, childhood obesity prevalence has increased up to threefold over the last three decades $(1,2)$. Recent Centers for Disease Control and Prevention (CDC) data
(2010) suggest that a slight decrease in obesity and morbid obesity in poor, preschool, nonnative American or Alaskan populations have decreased slightly during the previous 7 years (3). However, obesity continues to be a troubling attribute of America's young people. Furthermore, more than $30 \%$ of pediatric patients presenting for surgery in one large pediatric setting were found to be overweight or obese (OW) (4). These trends suggest a need to address specific healthcare needs of this 
population. Of particular concern is the potential lack of understanding regarding how to safely and effectively dose medications for OW children.

The absence of age and weight appropriate pharmacokinetic (PK) and pharmacodynamics (PD) data and pediatric labeling has led to 'off-label' the use of most drugs that are administered to children $(5,6)$, and has left dosing practices at the discretion and experience of the care provider. Although such dosing involves administering drugs to children based on lean body weight (LBW), actual body weight (ABW), or ideal body weight (IBW), no single approach is thought to cover all circumstances (7). The variable recommendations for dosing different medications may lead to inconsistencies in actual dosing practices, leaving children at risk of under- or overdosing. This risk may be greater for children who are OW.

In the perioperative setting, inappropriate dosing may contribute to ineffective pain treatment, infection prophylaxis, and other outcomes, which may negatively impact the quality and cost of patient care. Indeed, findings in adult studies have exposed potential risks for obese patients who received inappropriate dosing of anticoagulants and antibiotics $(8,9)$. It remains unknown whether similar risks are posed by potentially inappropriate dosing practices in the pediatric setting. This study therefore examined whether actual doses of commonly used medications were administered outside the recommended dose range to children who were OW by anesthesia care providers. Such data are needed to identify potentially ineffective dosing practices for children in this weight group.

The aim of the study was to determine whether children who are $\mathrm{OW}$ were at greater risk of receiving doses outside recommended doses compared to control weight (CW) (all children studied outside the OW group) children. We hypothesized that (i) OW children would more often receive medication doses outside the recommended ranges compared to children in the $\mathrm{CW}$ group; and (ii) OW children have a lower probability of being overdosed with medications dosed on actual weight (RDAW) than children in CW group.

\section{Methods}

Following Institutional Review Board approval and waiver of consent, this study included data retrospectively retrieved from the electronically captured anesthesia records (Centricity; GE Healthcare Information Technologies, Milwaukee, WI, USA). Data were included only for children aged 2 through 17 years who underwent anesthesia and received a single dose only of at least one of the commonly used medications of interest for a noncardiac procedure between February 2006 and May 2011. Children who remained intubated beyond the operating room setting or who had a history of hepatic or renal disease, neurological impairment, or sleep disordered breathing were excluded. In addition, patients without essential data (i.e., height or weight measurements) or who had unverifiable extreme height or weight data were excluded.

\section{Medication categories}

For this study, we focused on a few commonly used drugs from categories of agents that have data supporting recommended dosing based on ideal body weight (RDIW), actual body weight (RDAW), or lean body weight (RDLW). These classifications were based on limited pediatric drug dosing studies or recommendations or, more commonly, data from adult studies and expert interpretation of combined sources. Based on these limited recommendations, doses of midazolam and morphine were classified as RDIW (10-12) succinylcholine and neostigmine, as RDAW (11-15) and cisatracurium, and as RDLW (16).

Recommended dose ranges (see Table 4, Medication column) were calculated for each of these agents, and the actual doses administered were compared to these in the analyses. These actual dosing outcomes were defined as follows:

- Recommended dose: any dose between the minimum recommended dose for the agent less $10 \%$ and the maximum recommended dose plus $10 \%$.

- Under-dose: any dose administered more than $10 \%$ below the minimum recommended dose.

- Overdose: any dose administered more than 10\% above the maximum recommended.

\section{Weight categories}

Body mass index was calculated using the weight and height of each patient based on the standard formula (i.e., BMI $=\mathrm{Wgt}(\mathrm{kg}) /\left(\mathrm{Ht}(\mathrm{m})^{2}\right)$. Based on age- and gender-specific Centers for Disease Control and Prevention (CDC) growth charts, ${ }^{1}$ children were included in the control group if they were below or equal to the 85 th percentile, and in the OW group if above the 85th percentile. The medical records of children with documented BMI over the 85th percentile for age/gender were reviewed to ensure the accuracy of these classifications. Unverifiable data were excluded. Ideal body weight was determined by BMI method. Essentially, this

\footnotetext{
${ }^{1}$ www.cdc.gov/obesity/childhood/defining.html.
} 
method relates a child's actual BMI to the 50th percentile for age and gender on the CDC growth charts, which is considered their ideal body weight (17). Lean body weight defined as total body weight minus fat, expressed in kilograms was calculated using the formula $3.8 \times\left(0.0215 \times \mathrm{W}^{0.65} \times \mathrm{H}^{0.72}\right)(18,19)$.

\section{Statistical analysis}

Data analyses were performed with IBM SPSS Statistics for Windows, (Version 20.0, Armonk, NY, USA). All parametric data (e.g., age) are described as means \pm SD, and nonparametric data (e.g., gender) as $n(\%)$. Chisquare analyses were used to compare dosing outcomes (i.e., overdose or under-dose) between weight groups (i.e., OW vs CW). Odds ratios and 95\% confidence intervals were calculated for all comparisons.

\section{Results}

The sample included data from 10498 patients; their demographic characteristics are shown in Table 1 and the number of doses of each agent administered to the study groups is shown in Table 2. Overall, OW children had a $30 \%$ lower odds of receiving a recommended dose of any medication compared to the control group (see Table 3). Figure 1 depicts the number of children in each weight classification by age.

Table 4 describes the proportion of children in each weight group who received under- or overdoses with the agents in each drug category. Compared to children in the CW group who were administered morphine, those in the OW group were 3.5 times more likely to have received an overdose and nearly $70 \%$ less likely to have received an under-dose. Furthermore, the OW group had a significantly higher odds of receiving under-doses of succinylcholine and neostigmine.

\section{Discussion}

This study is the first to demonstrate that OW children have a significant risk of receiving doses of commonly

Table 1 Characteristics of the sample

\begin{tabular}{ll}
\hline & $n=10498$ \\
\hline Age in years (2 through 17) & $9.7 \pm 4.7$ \\
BMI & $19.8 \pm 5.7$ [4.2-69.6] \\
Weight groups & Male/Female \\
Control group & $4258(40) / 3158(30)$ \\
Overweight/Obese group & $1545(15) / 1537(15)$ \\
\hline
\end{tabular}

BMI, body mass index.

Data presented as mean \pm SD, [range], and $n(\%)$.
Table 2 Weight group distribution for medications

\begin{tabular}{lrr}
\hline $\begin{array}{l}\text { Medication } \\
\text { total doses }(n=10 \text { 509) }\end{array}$ & Control & Overweight/Obese \\
\hline Midazolam (1139) & $771(68)$ & $368(32)$ \\
Morphine (3418) & $2480(73)$ & $938(27)$ \\
Cisatracurium (1670) & $1145(69)$ & $525(31)$ \\
Neostigmine (3600) & $2477(69)$ & $1123(31)$ \\
Succinylcholine (682) & $415(61)$ & $267(39)$ \\
\hline
\end{tabular}

Data presented as $n(\%)$.

Table 3 Overall dosing comparisons between groups

\begin{tabular}{llll}
\hline & $\begin{array}{l}\text { Control } \\
\text { group } \\
(n=7288)\end{array}$ & $\begin{array}{l}\text { OW group } \\
(n=3221)\end{array}$ & OR $[\mathrm{Cl}] ; P$ value \\
\hline $\begin{array}{l}\text { Under-dosed } \\
\text { Recommended } \\
\text { dose }\end{array}$ & $\begin{array}{l}2317(32) \\
\text { Overdosed }\end{array}$ & $1232(38)$ & $1.33[1.22-1.45] ;<0.001$ \\
\hline
\end{tabular}

OW, overweight or obese.

Data presented as $n(\%)$; odds ratio [95\% confidence interval].

Odds ratios calculated with the 'recommended dose' as the reference group.

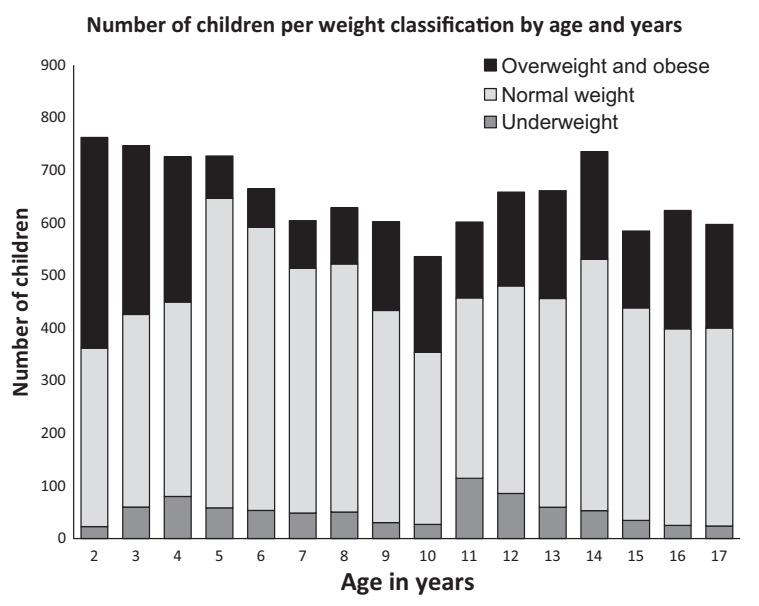

Figure 1 Number of children per weight classification by age.

used anesthetic medications outside the recommended doses. Casati stated that administering medications on total weight irrespective of recommendations may result in under- or overdosing and inappropriate dosing may contribute to ineffective treatment or potentiate adverse events (20). Consistent with our hypotheses, we found children in the OW group had a greater odds of being dosed with medications outside their recommended ranges. These findings suggest that children who are OW are potentially at greater risk of medication ineffectiveness or adverse events. 
Table 4 Comparison of specific dosing outcomes in the study groups

\begin{tabular}{|c|c|c|c|c|c|c|}
\hline \multirow{2}{*}{$\begin{array}{l}\text { Medication } \\
\text { [Recommended } \\
\text { dose range] }\end{array}$} & \multicolumn{3}{|l|}{ Under-dosed } & \multicolumn{3}{|l|}{ Overdosed } \\
\hline & Control & OW & $\begin{array}{l}\text { OR }[95 \% \mathrm{Cl}] \\
P \text { value }\end{array}$ & Control & OW & $\begin{array}{l}\text { OR }[95 \% \mathrm{Cl}] \\
P \text { value }\end{array}$ \\
\hline \multicolumn{7}{|c|}{ Recommended dose per ideal weight (kg I) } \\
\hline $\begin{array}{l}\text { Midazolam } \\
{\left[0.05-0.1 \mathrm{mg} \cdot \mathrm{kg} \mathrm{I}^{-1}\right]}\end{array}$ & $\begin{array}{l}545(71) \\
-32.1[-33 \text { to }-31]\end{array}$ & $\begin{array}{l}246(67) \\
-33[-34 \text { to } 31.5]\end{array}$ & $\begin{array}{l}0.8[0.6 \text { to } 1.1] ; \\
0.19\end{array}$ & $\begin{array}{l}21(3) \\
54 \text { [29.5 to } 79]\end{array}$ & $\begin{array}{c}14(3.8) \\
59 \text { [40 to } 79]\end{array}$ & $\begin{array}{l}1.4[0.7 \text { to } 2.8] ; \\
0.32\end{array}$ \\
\hline $\begin{array}{l}\text { Morphine } \\
{\left[0.025-0.1 \mathrm{mg} \cdot \mathrm{kg} \mathrm{I}^{-1}\right]}\end{array}$ & $\begin{array}{l}166(7) \\
-28[-30 \text { to }-26]\end{array}$ & $\begin{array}{l}21(2) \\
-31[-36 \text { to } 26]\end{array}$ & $\begin{array}{l}0.3[0.2 \text { to } 0.5] \\
0.00\end{array}$ & $\begin{array}{l}136 \text { (6) } \\
28 \text { [25 to 32] }\end{array}$ & $\begin{array}{l}157(17) \\
43 \text { [38 to } 48]\end{array}$ & $\begin{array}{l}3.5[2.7 \text { to } 4.4] \\
0.00\end{array}$ \\
\hline \multicolumn{7}{|c|}{ Recommended dose per actual weight (kg A) } \\
\hline $\begin{array}{l}\text { Neostigmine } \\
{[0.05-0.08 \mathrm{mg} \cdot \mathrm{kg}} \\
\left.A^{-1}\right]\end{array}$ & $\begin{array}{l}1335(54) \\
-30[-31 \text { to }-30]\end{array}$ & $\begin{array}{l}752(67) \\
-36[-37 \text { to }-35]\end{array}$ & $\begin{array}{l}1.7[1.5 \text { to } 2.0] \\
0.00\end{array}$ & $\begin{array}{c}19(0.8) \\
28[19 \text { to } 36.5]\end{array}$ & $\begin{array}{c}5(0.4) \\
27 \text { [10.7 to 43] }\end{array}$ & $\begin{array}{l}0.6[0.2 \text { to } 1.6] ; \\
0.27\end{array}$ \\
\hline $\begin{array}{l}\text { Succinylcholine } \\
{\left[1-2 \mathrm{mg} \cdot \mathrm{kg} \mathrm{A}^{-1}\right]}\end{array}$ & $\begin{array}{l}39(9) \\
-47[-56 \text { to }-38]\end{array}$ & $\begin{array}{l}44(17) \\
-36[-44 \text { to }-29]\end{array}$ & $\begin{array}{l}2[1.2 \text { to } 3.0] \\
0.006\end{array}$ & $\begin{array}{c}20(5) \\
32 \text { [18 to } 45]\end{array}$ & $\begin{array}{l}5(2) \\
29[-110 \text { to } 167]\end{array}$ & $\begin{array}{l}0.4 \text { [0.1 to } 1.01] ; \\
0.059\end{array}$ \\
\hline \multicolumn{7}{|c|}{ Recommended dose per lean weight ( $\mathrm{kg} \mathrm{L}$ ) } \\
\hline $\begin{array}{l}\text { Cisatracurium } \\
{\left[0.1-0.2 \mathrm{mg} \cdot \mathrm{kg} \mathrm{L}^{-1}\right]}\end{array}$ & $\begin{array}{l}125(10.9) \\
-32[-35 \text { to }-29]\end{array}$ & $\begin{array}{l}60(11.4) \\
-34[-39 \text { to }-28]\end{array}$ & $\begin{array}{l}1.1 \text { [0.8 to } 1.5] \\
0.76\end{array}$ & $\begin{array}{l}181 \text { (15.8) } \\
31 \text { [28 to 34] }\end{array}$ & $\begin{array}{c}76(14.5) \\
31 \text { [26 to } 36]\end{array}$ & $\begin{array}{l}0.9[0.7 \text { to } 1.2] \\
0.49\end{array}$ \\
\hline
\end{tabular}

Data are presented as the $n(\%)$ of the group (i.e., control or OW) that were under-dosed or overdosed with the agent shown and as $n(\%)$; percent difference from recommended dose expressed as mean [95\% Cl].

$\mathrm{OW}$, overweight or obese. Bold values denote statistical significance.

Of particular concern was the finding that children in the OW group were more likely to have received a dose of morphine that exceeded the recommended dose range for that agent. Excessive dosing of opioids may increase the risk of opioid-related respiratory depression and airway obstruction, which may be higher in children with obesity even when given in recommended doses (21-23). The known alterations in body make-up and physiology secondary to obesity (e.g., cardiac dysfunction, plasma protein concentration abnormalities, nonalcoholic steatohepatitis) negatively impact the utilization and clearance of medications (24). Findings from a recent study in normal weight and obese adults suggested differences in the clearance of fentanyl between lean and obese patients and further showed that dosing should be based on pK mass (i.e., LBW). The investigation concluded that lean dosing corrections may apply to dosing for other drugs in obese patients as well (25). These characteristics in conjunction with the variable growth and organ maturation phases throughout childhood $(12,26,27)$ make the obese child particularly vulnerable to adverse effects of medications, even when received in recommended doses. Doses that are in excess of those recommended, such as demonstrated for morphine in this study, may further increase these risks. Further study is needed to examine the potential consequences of dosing these agents in vulnerable children.

Obese and overweight children may also be susceptible to receiving ineffective doses of medications. Our data suggest that this may be particularly so for agents such as neostigmine and succinylcholine, which are recommended to be given based on actual weight. Our results indicate OW children were nearly twice as likely to receive an under-dose of these medications. This is concerning as under-dosing muscle relaxants may lead to motor activity, providing suboptimal conditions for endotracheal intubation or jeopardizing the integrity of the surgery. Under-dosing a reversal agent may subject a patient to inadequate ventilation due to prolonged neuromuscular blockade. Interestingly, Lemmens and Brodsky demonstrated that the onset time of maximum blockade in adults was the same whether the dose of succinylcholine was calculated on actual, ideal, or lean body weight. However, intubating conditions were rated as poor, significantly more often in the ideal or lean body weight calculation groups (28). In addition, Suzuki, et al. (29) found that spontaneous recovery from neuromuscular blocking agents is significantly longer in overweight and obese than normal weight females. Although our data do not explain why children were under-dosed, it is possible, given the paucity of PK and PD data and dosing recommendations for children, that clinicians may have been uncomfortable administering doses that seem to be excessive compared to those usually administered in the general population of normal weight children. If children behave in similar fashion, the implications of prolonged paralysis or incomplete reversal may be troublesome. Our data suggest that clinicians' actual dosing practices appear to regress to 
giving mean doses that fall within a recommended range for $\mathrm{CW}$ children. It remains unknown how these actual dosing practices may have affected outcomes in children in these groups.

\section{Limitations}

The retrospective nature of this study and the use of electronic data capture introduce the potential for reporting bias, as well as a selection bias. It is possible that patients were misclassified into weight groups given the known documentation errors that can occur. Although we attempted to minimize the potential for error by verifying the weights, heights, and BMI of all children in the extreme weight groups, it remains possible that some children were misclassified. Additionally, we cannot dismiss the potential for error in the documented doses administered. Such error may have led to a selection bias, where patients who received some of these agents were excluded. Next, we classified medications into dosing groups and defined their recommended doses based on the limited available data for children and from extrapolated data regarding their chemical properties, drug metabolism, and clearance in adults. Most of these data were conducted in healthy, normal weight populations $(5,30,31)$. It remains unknown how these data apply to normal vs overweight and obese children, particularly in the absence of specific dosing recommendations. Additionally, we treated the obese patients as a homogenous group even though children who are clinically severely obese have a distinct physiologic profile that may have influenced dosing practices. Furthermore, it is possible that actual doses administered reflected personal experience, preferences, or perhaps an individualization of care due to some unknown patient characteristic. Future prospective studies could explore dosing based on BMI categories. Lastly, findings represent the dosing practices at one institution where the attending anesthesiologists are expert in the care of children, and may therefore not be generalized to other settings. Our exclusion of patients with conditions that are known to potentially influence drug dosing may have eliminated some of these possibilities, making the data more reflective of dosing practices for the 'average' pediatric patient.

\section{Conclusion}

These data suggest that OW children may be susceptible to receiving doses of commonly administered anesthetic agents outside the recommended ranges. Such findings may reflect the absence of pediatric dosing recommendations in general or for more specific guidelines for children who are OW. It remains unknown whether or how such dosing practices relate to anesthetic outcomes in children.

This study identifies inconsistencies in dosing practices for children across weight classifications. This is likely due to insufficient evidence to guide clinical decisions regarding optimal dosing. Future research should be directed at providing such an evidence base.

\section{Acknowledgments}

Approval by University of Michigan IRBMED: HUM 00004487. No external funding. No disclosures for any Author/Co-Authors.

\section{Conflict of interest}

No conflicts of interest declared.

\section{References}

1 Ogden CL, Carroll MD, Curtin LR et al. Prevalence of overweight and obesity in the United States, 1999-2004. JAMA 2006; 295: 1549-1555.

2 Hedley AA, Ogden CL, Johnson CL et al. Prevalence of overweight and obesity among US children, adolescents, and adults, 19992002. JAMA 2004; 291: 2847-2850.

3 Pan L, Blanck HM, Sherry B et al. Trends in the prevalence of extreme obesity among US preschool-aged children living in low-income families, 1998-2010. JAMA 2012; 308: 25632565.

4 Nafiu OO, Ndao-Brumlay KS, Bamgbade OA et al. Prevalence of overweight and obesity in a U.S. pediatric surgical population. $J$ Natl Med Assoc 2007; 99: 46-48, 50-1.
5 Schirm E, Tobi H, de Jong-van den Berg LT. Risk factors for unlicensed and off-label drug use in children outside the hospital. Pediatrics 2003; 111: 291-295.

6 Tobin JR, Shafer SL, Davis PJ. Pediatric research and scholarship: another Gordian knot? Anesth Analg 2006; 103: 43-48.

7 Han PY, Duffull SB, Kirkpatrick CM et al. Dosing in obesity: a simple solution to a big problem. Clin Pharmacol Ther 2007; 82: 505-508.

8 Forse RA, Karam B, MacLean LD et al. Antibiotic prophylaxis for surgery in morbidly obese patients. Surgery 1989; 106: 750-756; discussion 6-7.

9 Spinler SA, Ou FS, Roe MT et al. Weightbased dosing of enoxaparin in obese patients with non-ST-segment elevation acute coronary syndromes: results from the CRUSADE initiative. Pharmacotherapy 2009; 29: 631-638.

10 Baines D. Anaesthetic considerations for the obese child. Paediatr Respir Rev 2011; 12: 144-147.

11 De Baerdemaeker LE, Mortier EP, Struys MM. Pharmacokinetics in obese patients. Contin Educ Anaesth Crit Care Pain 2004; 4: 152-155.

12 Mortensen A, Lenz K, Abildstrom $\mathrm{H}$ et al. Anesthetizing the obese child. Pediatr Anesth 2011; 21: 623-629.

13 Bentley JB, Borel JD, Vaughan RW et al. Weight, pseudocholinesterase activity, and succinylcholine requirement. Anesthesiology 1982; 57: 48-49. 
14 Lemmens HJ. Perioperative pharmacology in morbid obesity. Curr Opin Anaesthesiol 2010; 23: 485-491.

15 Rose JB, Theroux MC, Katz MS. The potency of succinylcholine in obese adolescents. Anesth Analg 2000; 90: 576-578.

16 Leykin Y, Pellis T, Lucca M et al. The effects of cisatracurium on morbidly obese women. Anesth Analg 2004; 99: 1090-1094, table of contents.

17 Phillips S, Edlbeck A, Kirby M et al. Ideal body weight in children. Nutr Clin Pract 2007; 22: 240-245.

18 Peters AM, Snelling HL, Glass DM et al. Estimation of lean body mass in children. $\mathrm{Br}$ $J$ Anaesth 2011; 106: 719-723.

19 Green B, Duffull SB. What is the best size descriptor to use for pharmacokinetic studies in the obese? Br J Clin Pharmacol 2004; 58: 119-133.

20 Casati A, Putzu M. Anesthesia in the obese patient: pharmacokinetic considerations. $J$ Clin Anesth 2005; 17: 134-145.
21 Brown KA, Laferriere A, Lakheeram I et al. Recurrent hypoxemia in children is associated with increased analgesic sensitivity to opiates. Anesthesiology 2006; 105: 665-669.

22 Gross JB, Bachenberg KL, Benumof JL et al. Practice guidelines for the perioperative management of patients with obstructive sleep apnea: a report by the American Society of Anesthesiologists Task Force on Perioperative Management of patients with obstructive sleep apnea. Anesthesiology 2006; 104: 1081-1093; quiz 117-8.

23 Schwengel LM. Perioperative management of children with obstructive sleep apnea. Anesth Analg 2009; 109: 60-75.

24 Cheymol G. Effects of obesity on pharmacokinetics implications for drug therapy. Clin Pharmacokinet 2000; 39: 215-231.

25 Shibutani K, Inchiosa MA Jr, Sawada K et al. Accuracy of pharmacokinetic models for predicting plasma fentanyl concentrations in lean and obese surgical patients: derivation of dosing weight ("pharmacokinetic mass"). Anesthesiology 2004; 101: 603-613.

26 Holford N. Dosing in children. Clin Pharmacol Ther 2010; 87: 367-370.

27 Samuels PJ. Anesthesia for adolescent bariatric surgery. Int Anesthesiol Clin 2006; 44 17-31.

28 Lemmens HJ, Brodsky JB. The dose of succinylcholine in morbid obesity. Anesth Analg 2006; 102: 438-442.

29 Suzuki T, Masaki G, Ogawa S. Neostigmineinduced reversal of vecuronium in normal weight, overweight and obese female patients. Br J Anaesth 2006; 97: 160-163.

30 Anderson GD, Lynn AM. Optimizing pediatric dosing: a developmental pharmacologic approach. Pharmacotherapy 2009; 29: 680690.

31 Porter RM, Thrasher J, Krebs NF. Implementing a pediatric obesity care guideline in a freestanding children's hospital to improve child safety and hospital preparedness. $J$ Pediatr Nurs 2012; 27: 707-714. 